Original Article

\title{
Beyond the moment: Influence of a co-facilitated education intervention on practitioners' recovery beliefs and practices
}

\author{
Agnes Higgins, ${ }^{1}$ (D) Rebecca Murphy, ${ }^{1}$ (D) Carmel Downes, ${ }^{1}$ (D) Jennifer Barry, ${ }^{1}$ (D) \\ Mark Monahan, ${ }^{1}$ (D) Louise Doyle ${ }^{1}$ (D) and Patrick Gibbons ${ }^{2}$ (ID) \\ ${ }^{1}$ School of Nursing \& Midwifery, Trinity College Dublin, Dublin, and ${ }^{2}$ Celbridge Adult Mental Health Services, \\ Kildare, Ireland
}

\begin{abstract}
Despite health policy and research increasingly advocating for recovery-enabling principles to be better integrated into mental health services, finding solutions to enhance the translation of recovery policy into practice remains a challenge. This study sought to understand whether a co-facilitated group education intervention for service users and family members reached beyond the intervention and impacted the everyday recovery promoting beliefs and practices of the practitioners involved and the wider organization. The study employed a qualitative design involving semi-structured interviews with a purposively selected sample of 28 participants (mental health nurses and other members of the multidisciplinary team) who were involved in delivering the intervention. Data were analysed using thematic analysis, with the assistance of NVivo. Participants reported that not only did involvement with the programmes help them reconnect with the contextual realities of service user and family members lived experience, but it enabled them to move beyond traditional power relationships and pathologizing discourses. Having engaged with and experienced the feasibility and positive impact of the co-facilitation process practitioners' self-efficacy around partnership working and co-production was enhanced. In addition, those involved demonstrated a willingness to challenge paternalistic practices and advocate for the perspectives of service users and families to be further embedded within the organizational infrastructure and operational spaces. Providing mental health practitioners with real-life examples of partnership working and peer support in action within a co-facilitated psychoeducation context has potential to be a forum for promoting second-order change around recovery-oriented practice within mental health services.
\end{abstract}

KEY WORDS: education, implementation science, mental health recovery, mental health services, organizational change.

\footnotetext{
Correspondence: Agnes Higgins, School of Nursing and Midwifery, Trinity College Dublin, 24 D’Olier Street, Dublin, Ireland. Email: ahiggins@tcd.ie

Declaration of conflict of interest: The authors have no other conflicts of interest to declare.

Authorship statement: All authors listed meet the authorship criteria according to the latest guidelines of the International Committee of Medical Journal Editors, and all authors have contributed and are in agreement with the manuscript. AH, MM, LD, and PG designed the study. RM, JB, CD, and AH collected and analysed the data. AH, RM, CD, JB, MM, LD, and PG drafted and commented on the paper. Agnes Higgins, PhD, MSc, BNS, RPN, RGN.

Rebecca Murphy, PhD, MSc, BA.

Carmel Downes, MSc, BSocSc.

Jennifer Barry, BSc, HDip, MSc.

Mark Monahan, PhD, MSc, BNS, RPN.

Louise Doyle, PhD, MSc, BNS, RPN.

Patrick Gibbons, MB, BCh, MRCPsych, MD.

Accepted May 032020.
}

(C) 2020 Australian College of Mental Health Nurses Inc. 


\section{INTRODUCTION}

Recovery as a concept is built into mental health policy around the world, including the Republic of Ireland (Department of Health \& Children 2006; Health Service Executive 2017). While the early focus was on understanding the meaning and experience of recovery and differentiating between clinical and personal recovery (Slade 2009), the discourse has now shifted to how mental health services provide recovery-oriented care and support to people to live meaningful and fulfilling lives (Chester et al. 2016; Slade et al. 2014; Stickley et al. 2016). In line with this move, there is an increasing call for recovery-enabling principles to be better integrated into mental health services both nationally and internationally (Gilburt et al. 2013; Mental Health Reform 2012; Ramon et al. 2007; Slade et al. 2012). Achieving a system change from a traditional hierarchical biomedical approach to a more recovery-oriented approach is not without its challenges (Bonny \& Stickley 2008; Slade et al. 2012). Building recovery-oriented services 'requires a significant paradigm shift in how people conceptualize mental illness and distress, as well as how people living with mental distress and illness are understood and supported' (Higgins \& McGowan 2014:66)

In the Republic of Ireland, it is over 10 years since the expert group charged with developing the national mental health policy stated that 'A recovery approach should inform every level of the service provision so service users learn to understand and cope with their mental health difficulties, build on their strengths and resourcefulness, establish supportive networks, and pursue dreams and goals that are important to them and to which they are entitled as citizens' (Department of Health \& Children 2006: 5). Similar to international experiences (Le Boutillier et al., 2015), the challenges in translating recovery policy into practice are equally apparent within the Irish mental health services. While some improvement has been noted in the knowledge and attitudes of healthcare practitioners towards recovery (Cleary \& Dowling 2009; Gaffey et al. 2016), there is a concern that services remain embedded in traditional paradigms (O'Feich et al. 2019).

Recovery education has been the primary intervention internationally in the move from policy aspirations to practice translation. However, systematic reviews have identified challenges with education approaches that are decoupled from the every-day practice within the mental health services. Following a systematic review of recovery education, Eiroa-Orosa and GarcíaMieres (2019) concluded that while education activities made a moderate impact on the beliefs and attitudes of mental health professionals, the impact on practice was less evident. The authors of this review also suggest that although organizations were allocating funds to education, they prevented change by not providing real and tangible support for changes to be implemented and sustained within practice (Eiroa-Orosa \& GarcíaMieres 2019). Similarly, Crowther et al. (2019) in a recent systematic review on action and outcomes of recovery colleges report that while recovery colleges impact community attitudes, having developed independently of the mental health services and being more outward facing in their orientation, they have reduced reach and impact on the culture and practice within the mental health services.

Although interpretations of recovery differ (McCabe et al. 2018; Onken et al. 2007), core recovery-enabling practices emphasize expertise by experience, shared decision-making, and partnership approaches with service users and family members (Repper 2012; Stickley et al. 2016). If services are to develop more shared and collaborative ways of working (as envisioned in national policy on recovery), it is crucial to find ways to empower and support frontline staff to share power and to accept the value of user and family expertise. Although the provision of education on the theory of recovery and recovery principles is important in terms of enhancing knowledge or improving attitudes, self-efficacy is also critical and is a component of most behaviour change theories (Kwasnicka et al. 2016). To enhance self-efficacy, practitioners require real concrete examples of recovery-oriented practices in action. It is only through engagement in and reflection on action that practitioners will develop the practical wisdom necessary to work in a recovery-oriented way with service users and family members. One possible approach to enhancing competency in this area is to develop recovery-oriented psychoeducation interventions within services that are co-produced and co-facilitated by practitioners and peers.

As there is an already extensive research base supporting the positive impact of psychoeducation for both service users and family members (Brooke-Sumner et al. 2015; Lucksted et al. 2012; McFarlane et al., 2003), this paper does not seek to report impact on service users or family outcomes; rather, it seeks to understand whether a co-facilitated group education intervention reached beyond the intervention and 
impacted the everyday recovery promoting beliefs and practices of the practitioners involved and the wider organization. The data which this paper is based on is part of a larger funded study into the structural, cultural and systemic processes thatenabled or hindered the adoption, implementation and sustainability of a psychoeducation programme within the mental health system.

\section{EOLAS Intervention}

The psychoeducation intervention (called EOLAS, which is the Irish word for knowledge) was developed in collaboration with service users, family members, and mental health services, and consists of two information programmes (one for people who have been diagnosed with schizophrenia spectrum or bipolar disorders and a parallel programme for their family members or other supporters). One of the core differences between the programme and some other psychoeducation programmes is the dual nature of its development and facilitation as it combines the experiential knowledge of peers (service users and family members) with the expertise of clinicians. Each programme is jointly facilitated by either a service user or family member, and a clinician who are drawn from the mental health service where the programme is being delivered. The programmes consist of 8 weekly sessions, each of 90minute duration with time allocated for discussion and sharing of experiences. While no theoretical perspective is privileged, and information on medical, psychological, and social perspectives is presented, all the programme content has been developed within a recovery ethos and underpinned by the principles of adult learning. In addition to having a handbook to guide each session, all facilitators (clinicians and peers) are provided with an education programme to support the development of co-facilitation skills and the delivery of the programme.

The programme content is dynamic and revised through a process of continuous evaluation, feedback, and consultation with service users and family members. More detailed information on the participatory approach taken to co-designing the programmes, the programme content, and the process used to prepare the facilitators to co-deliver the programme are reported elsewhere (Inserted after review). In addition, the impact of the programmes on service users/family attendees, which was the primary motivation for developing the programmes, has also been reported previously (inserted after review).

\section{METHODOLOGY}

\section{Aim}

The aim of this aspect of the study was to explore participants' views on whether the EOLAS psychoeducation interventions impacted recovery beliefs and practices beyond the programme.

\section{Methods}

The study design was qualitative descriptive, involving the collection of data through individual and focus group interviews. Qualitative descriptive research is directed at providing an in-depth description of an experience or event (Doyle et al. 2019). It facilitates the understanding of human experience in its unique context through flexible and dynamic research processes, selecting the most appropriate methods to meet the aim and objectives of a study. While the research processes utilized in a qualitative descriptive design are inductive, they are careful to remain near to the data in the analysis and interpretation of participants' experiences (Doyle et al. 2019).

\section{Data collection}

Data were collected using semi-structured, audiorecorded interviews (one to one and focus group). Due to limited resources and a desire to capture the views of as many participants as possible from services that were geographically spread, the research group decided to provide potential participants with the option of either a focus group interview or an individual interview. The option of a focus group also facilitated the collection of data from potential participants who were meeting as a group for other EOLAS-related issues. To guide data collection, the team developed an interview schedule which included questions about impact of the intervention at an individual, team, and organizational level (Table 1). As the schedule was broad in nature and to ensure consistency in data collection, the same schedule was used for both the individual and focus group interviews. Two members of the research team (RM and JB) collected the data between late 2018 and 2019.

\section{Recruitment}

Purposive sampling was used to select participants from mental health services that were involved in delivering the intervention. The services involved had all 
opted to deliver the intervention because of a perceived deficit within the service provided to people experiencing psychosis. All of the sites involved were part of the statutory mental health services in the Republic of Ireland; thus, they delivered a range of inpatient and community services. The services involved were also drawn from different healthcare jurisdictions, thus ensuring geographic spread and urban and rural divide.

Participants were chosen based on their ability to inform the study objectives; thus, participants with different roles and duration of experience with EOLAS were included. For this aspect of the study, two different groups of participants were recruited, practitioner facilitators and coordinators. Facilitators were mental health practitioners who had undergone a training programme to deliver the programme and had direct experience of co-facilitating the programmes. The coordinators were also practitioners who had responsibility for coordinating and implementing the programmes within a particular service; thus, they were in a position to provide an organizational perspective on how the programme may have impacted changes at organization level.

For recruitment, potential participants (facilitators and coordinators who had previously provided consent to be contacted by the EOLAS project team) were sent a letter of invitation and an information brochure, together with an invitation to contact a member of the research team if they were willing to participate, in either an individual or focus group interview. Once a potential participant made contact, all questions were answered and a time for either an individual or focus group interview was arranged.

\section{Ethical approval and access to participants}

Ethical approval was granted by the University's Research Ethics Committee and the ethics committees

TABLE 1 Impact questions within the interview schedule

- In your experience, what have been the long-term benefits of your involvement in the EOLAS programme? (e.g. Knowledge, Skills, Attitudes). If yes, give examples

- Has your involvement in EOLAS changed your relationship with service users/family/clinicians/mental health team in any way?

- Describe/provide examples of how involvement in EOLAS has impacted upon your interactions with and/or understanding of service users/family members/clinicians/mental health team.

- Do you think EOLAS has had an impact on systemic culture and practice in the wider mental health team and service? If yes, give examples of the services involved. The Director of Nursing at each site provided access to participants following communication with a member of the research team. To ensure informed consent, participants were given written and verbal information about the study and were required to provide written and verbal consent for the interviews. In addition, the principle of process consent was applied by the researchers at each encounter.

\section{Data analysis}

Interviews were transcribed and the data cleaned and inputted into NVivo (NVivo 2018) for the process of analysis. Using thematic analysis, guided by the constant comparative process (Glaser \& Strauss 1967) data were systematically coded for ideas and concepts around impact. Emerging codes were compared for similarity and differences, and merged into higher themes. Merging of data from different sources did not pose a problem. While, in accordance to their role, facilitators and coordinators spoke in varying depths to the three core themes, the data did not differ substantially in substance. The data did however differ in depth depending on mode of data collection. In contrast to the short and succinct comments of the focus group participants, participants in the individual interviews tended to provide more elaborate responses to questions. To enhance the rigour of the qualitative analysis, data were analysed by more than one person and findings compared. Analysis was completed by three team members (RM, CD, and $\mathrm{AH}$ ), and the final coding was agreed by consensus (AH and RM), thus ensuring consistency in data interpretation. Emerging themes were evident across both data sources, and data recurrence was observed, with no new themes or information emerging, indicating that data saturation had been reached.

\section{Profile of sample}

In total, 12 facilitators and 16 coordinators were interviewed, the majority of whom were female, working in the disciplines of nursing or social work (Table 2). Twelve of the EOLAS coordinators also had experience of facilitating the EOLAS programmes. The facilitators were, on average, working in the mental health services for 16 years $(\mathrm{M}=15.58, \quad \mathrm{SD}=8.93, \quad$ range $=4$ 29 years) and involved with EOLAS for four and a half years $(\mathrm{M}=4.5, \quad \mathrm{SD}=2.38, \quad$ range $=1-6$ years $) . \quad$ On average, they had delivered EOLAS programmes three 
times $(\mathrm{N}=9, \quad \mathrm{M}=3, \quad \mathrm{SD}=1.83, \quad$ range $=1-5) . \quad$ On average, the EOLAS coordinators had been working in mental health services for 16 years $(M=16, S D=11$, range $=3-40$ years) and involved with EOLAS programmes for approximately 3 and a half years $(\mathrm{M}=3.43, \mathrm{SD}=1.89$, range $=1-7$ years $)$.

\section{FINDINGS}

Three core themes emerged in the thematic analysis, (i) reconnecting with the contextual realities of people's lives, (ii) recognizing and working with families, and (iii) the integration of co-production into service delivery. Data supporting each theme are outlined in Table 3.

\section{Reconnecting with the contextual realities of people's lives}

Having spent many years working within the mental health services, participants reported that the EOLAS programmes helped them to reconnect to the contextual realities of people's lived experience. They spoke of gaining an enhanced insight into and renewed understanding of both service users' and family members' everyday experiences, which in turn strengthened their empathy and inspired a greater willingness to take meaningful account of their needs within their everyday practice (A.1, A.2, A.3). In addition to EOLAS helping to keep staff 'grounded' and 'empathetic' (A.4), it motivated them to deliver their best standard of care (A.5). Participants commented that they had changed their approach to be less judgemental and more open (A.6). Participants recounted that the learning and deconstruction of previously held assumptions that EOLAS had facilitated informed a new mindset and change in their practice. The programme was appraised as providing space for deconstruction of assumptions and an opportunity to really hear a person's perspectives rather than having their distress/illness and needs defined by practitioners and the mental health services (A.7). Participants spoke of gaining a deeper understanding of service users' confusion about how to navigate services in the absence of proper information (A8), the specific role of each discipline in the Mental Health Team (A.9) and their struggles to attend services and actively participate (A.10, A.11). As a result, the participants began to reflect on their own practice and question paternalistic care practices (A.12), to advocate upwards for changes within services (A.13) and to speak about their learning to colleagues (A.14).
TABLE 2 Overview of interviewees by method of data collection and role in EOLAS

\begin{tabular}{|c|c|c|c|c|}
\hline Role in EOLAS & Gender & Discipline & $\begin{array}{l}\text { Individual } \\
\text { interview }\end{array}$ & $\begin{array}{l}\text { Focus } \\
\text { group }\end{array}$ \\
\hline EOLAS facilitators & $\begin{array}{l}\mathrm{F}=10 \\
\mathrm{M}=2\end{array}$ & $\begin{array}{l}\text { Nurses }=6 \\
\text { Social } \\
\text { worker }=4 \\
\text { Occupational } \\
\text { therapist }=2\end{array}$ & 2 & 10 \\
\hline $\begin{array}{l}\text { EOLAS } \\
\text { coordinators ( } 12 \\
\text { with experience of } \\
\text { facilitating the } \\
\text { programmes) }\end{array}$ & $\begin{array}{l}\mathrm{F}=11 \\
\mathrm{M}=5\end{array}$ & $\begin{array}{l}\text { Nurse }=8 \\
\text { Social } \\
\text { worker }=7 \\
\text { Psychiatrist }=1\end{array}$ & 7 & 9 \\
\hline
\end{tabular}

Some participants reported how the programme afforded medical colleagues, through their participation as a guest speaker in the programmes, an opportunity to hear in greater and more honest detail the challenges faced by service users (A.15).

\section{Recognizing and working with Families}

Participants recounted how EOLAS gave them an insight into the feelings that family members' experience, including isolation, guilt, stigma, and anger, and the processes of loss and acceptance that families goes through when dealing with the mental health/illness of a loved one. This newfound empathy in turn heightened clinicians' awareness of the need to support families (B.1, B.2, B.3). Participants reflected on how they were able to take these learnings from EOLAS and apply it in their clinical practice. They reported adopting more inclusive approaches towards families, including discussing the involvement of family with service users, making concerted efforts to meet family members, sharing information without breaching confidentiality, emphasizing the importance of self-care, and educating others about the role and importance of family in recovery (B.4, B.5). In observing that participation in EOLAS increased the engagement of clinicians with family members, other members of the multidisciplinary team followed suit, resulting in a subtle shift in service culture (B.6).

Participants who altered their individual practices following involvement with EOLAS also sought to bring about change within the wider service where they worked. For example, they advocated for changing the process of taking a collateral history from family members from a tick box approach to a more engaged and inclusive approach (B.7). Other noteworthy ways in which EOLAS inspired service changes included 
TABLE 3 Data to support themes

\section{Reconnecting with the contextual realities of people's lives}

A.1 I think what I got out of it... is to know better what we think we know. When you're working a long time in mental health you hope you wouldn't lose your compassion... But sometimes you get a bit immune to the whole experience. So what I found was that just listening, even at the training [in co-facilitation]. to the service users, the family members. I really felt it was like, I was hearing it for the first time.... it brought it back to somebody's kitchen. . to the real lived experience of mental health. . . You've kind of forgotten what it [living with mental health issues] might be like. (F04; FG)

A.2 I thought I understood what families were going through. What service users were going through. But I didn't fully understand until I got involved in EOLAS. maybe it's the forum. . . the fact that there was a peer facilitator, but people felt very relaxed to tell their story. And so many stories that were of such a profound nature and you really began to feel that you were in their space. You know they [lecturers] talk about empathy and being in somebody's shoes. And it wasn't just me that felt that. An awful lot of the [clinical] facilitators would say the same. Only this week, I spoke to facilitator in [names another service] and she just was blown away blown away by the experience. She said, she's eleven years in nursing and she never experienced anything like this. (F02; II)

A.3 Because as I said they [facilitators] learn to understand the impact. The way I would describe it they look past the symptoms and they see the person. And I think that has been the biggest impact. It has changed practice, nurses have said 'this is changed my practice' (C3; II)

A.4 It's (being involved) keeping you grounded and keeping you empathetic. (C14; FG)

A.5 While you're observing them \{service users and families] they're observing you and you just don't realise that and you're like [after EOLAS) whoa, pull up my socks a bit. [...] I think it’s [getting that] very healthy insight, absolutely. (C07; II)

A.6 And even in my own conversations it's made me be so much less judgemental, ... it could be me sitting there just as much as them. Reminds me to be much more real in what I'm doing with people and you know when people feedback, they will often say you've made me feel normal, or, you've related to me and I don't feel judged. (F11; FG)

A.7 We done a lot of training [aspects of recovery and mental health] up until then and it [EOLAS] was very different, between you're there with other colleagues and people from different professions. But you're all kind of doing the same thing. But you know to listen [during EOLAS] to other people's [service users and family members] experience of mental health services... what's going on, because they let their guard down way more than they ever had before. It was our idea about what they needed, or what was wrong. It [EOLAS experience] was a real awakening, we [professionals] were so wrong. It was eye opening, what their goals were ... what they seen as important was very different to what we [professionals] thought. (F12; FG)

A.8 [...] so it really made me aware that I'm comfortable and I know the service but these people don't, and they will just say yes and go along $t$ because they're either very unwell or they just don't want to admit that they're a bit lost in what's happening. .. I suppose how you deal with people, definitely, just on that basic level. It made a huge change for me ... it's a different mind frame from what we would have been trained in and worked in, it is a different mind frame. And the more you're working in it [cofacilitation] it just becomes your way of practicing, as it is totally different. (COI:II)

A.9 The biggest thing was not know if they're seeing a psychiatrist or a psychologist and they don't really know. . they don't know the difference [between people]... they don't really know why they're going to see them. You explain to them [during the programme] about psychology, it is completely different to psychiatry. Psychiatry is all around diagnosis and medication and psychology is more, the psychological approach, talk therapy. Since then [facilitating EOLAS] I see it with a lot of people, even outside of the service, they were actually totally confused about roles (C06; II)

A.10 You've more appreciation and acknowledgement of the struggles of people, even though there's a facade that we all put on, behind that there's so much struggle [to get to programme and services], but sometimes I don't think we acknowledge it [peoples struggles] appropriately. (F03; FG)

A.11 The other learning are shortfalls in the services. Whether it's access, phones not being answered. Access to buildings, the planning of outpatients. (C05; II)

A.12 EOLAS did make us stop and look more objectively about how we are treating people. What information they're getting. Are we deciding whether they hear about this? And that paternalistic kind of approach. It's made such a [difference]... really stripping all that back. Because, there was things, we didn't realise 'til we were in a room with these people, really listening to their experiences. We didn't know that they didn't know who you were, who the consultant was, who the OT was, or what that [titles] meant. We presumed that they did know, of course they know, why wouldn't they know. Or that their diagnosis wasn't explained to them. That they or their family weren't given time, or information, or support. We just presumed; we really didn't think too deeply into these things. And it made us then step back, because these are people we had looked after and we knew. And I kind of said, I never knew that that was your experience, I didn't realise that that had happened. Because we never asked the questions. It [participating] did make us really stop and think and reflect and say, okay this is not the way we want to do things. (F11;FG)

A.13 And one particular coordinator said, I'm bringing a list to the management team of issues] that have been raised [within the groups]. They [management]won't like them a lot but they need to hear them. (C04;II)

A.14 One nurse said to me, I couldn't wait to leave the group to go back and tell my colleagues about what I'd learned. (C06; II) 
A.15 It's really good learning for them [doctors-guest speakers] and that has been fed back to us... because, they hear things at that session that they probably will never hear. And the fears that people have both family members and service users in terms of aggression and violence and the potential for different things to happen. They hear what service users are really thinking about those things. So there's learning both sides. I think it [learning] filters out of the room because you will hear oh such and such a one was doing the [EOLAS] session and couldn't really believe the way people described their symptoms or you know what family members thought [...] (C03;II)

\section{Recognizing and Working with Families}

B.1 I think the, the loss, the frustration, the anger, the sadness, the acceptance, that whole piece with family members and the isolation has really made me probably more empathic when I first meet a family member, or more aware of how they might be feeling because EOLAS members have taught me that, whereas I couldn't have known that before, I could have had my theories, but I, I don't think I would have known on such a human level so that's been, probably really helped my practice. (F09; FG)

B.2 [...] my learning from EOLAS is how alone family members feel and I understand the loss now and the stigma and anger, which I probably wouldn't have known had I not done EOLAS, so it's massive learning for me. (F04; FG)

B.3 ..I do think there is that piece where you just think as well God, yeah, we don't look after the families enough, we don't acknowledge their loss and, you know, as much as it has to be hope inspiring at the end there is a huge piece around, you know, and their guilt and, and looking after themselves and all those pieces and I think that maybe from a clinician point of view absolutely, we learn an awful lot. (F05; FG)

B.4 So I would have said you know hugely, hugely satisfying in your professional work you know and also I think that EOLAS is useful. I would work with people on one to ones but I'm able to kind of use part of the EOLAS, in terms of my work with them you know and useful when you meet family members around you know what happens: what do you have difficulty with in the management of Johnny on any particular day or Billy at night or when are the times you find it difficult? You know you're able to use some of that EOLAS stuff to kind of tease out where we need to go with this, you know. So you're able to use it kind of, you're certainly able to use the knowledge of it in your day to day work as well. (C01; II)

B.5 It definitely has changed our practice. And particularly around families [...] Every person I meet I say bring your loved one along with you. And before I used to be, oh they brought their mother or their husband is here, oh I have to see them as well. I'm delighted now, when I see someone coming in. I can't wait to meet them. I'll always invite them. It made me think that if someone says, I don't want my mother involved, I don't want my husband to know... Whereas now I ask them why, why not?... I've the conversation... and I often say to a family member, are you okay, how are you minding yourself and giving them information about things... how to navigate the system. They don't know what the outpatients is. They don't know who's on the mental health team. They don't know where to go if their loved one gets sick, or this happens again ... And educating nursing colleagues and students around families, the importance and difference it makes in a person's recovery to have someone in their network that understands what's going on. So being a family friendly service is a big, we've totally taken that onboard now. (F03; FG)

B.6 I think there's a shift with [medical] consultants now as well, they used to kind of think it's all confidentiality issues, but actually we can support families without talking specifically about their family member and I think that's been probably the most useful learning down in our area. (F10; FG)

B.7 It has impacted as a service. . The staff we work with haven’t necessarily done EOLAS. But we would be telling them. Like when we came down here (to service), the word was collateral and everyone had to tick the box. ... it didn't mean they always spoke to families because it was like the consultant, they got collateral. But it was done in a tick box way. I'm just ringing (consultant) to see if have you any information. And the person didn't know what to be nearly saying [to the family] .... And we are like that's not the way this should happen [...] it's [family involvement] is much more inclusive. (F11; FG)

B.8 Certainly, meeting with families as part of the inpatient and discharge process has become much more frequent and very much part of the discharge plan, and I do think EOLAS has played some part in it - yeah, because it became more normal to engage with family. And some of them (psychiatrists) are hugely anxious about attending [the EOLAS evening] and once we kind of did that (have them attend), like its why don't we do this [involve families] all the time - so I do think that EOLASs actually had some role to play in that. (C13; FG)

B.9 Out of EOLAS they [team] started running care planning meetings... they'd bring in families with the service users and service provider and we'd look at the care plan and see what the needs were... cause they felt it was so good that three people, the service provider, the service user and a family member would be in the room.... You know it was an idea that came out of EOLAS... we were able to bring it (learning) back into our own work on a daily basis (F02; II)

B.10 They're [staff facilitators] eyes were hugely opened to a whole new way of engaging with the family member and that was very beneficial, that was very visible also to the other MDT [Multi-Disciplinary Team] members, that suddenly there was a different kind of way of engaging with the family. (C12; FG)

Integration of the co-production into service delivery

C.1 I just thought that whole coproduced part, you know, family service users, clinicians all in the one room, it just, it was overwhelming, but it just blew me away really, in a really nice way, and I've never looked back really. (C14; FG) 
C.2 You know it's very hard to sort of shift, to turn off the switch [of paternalism and being a professional], but being able to have a more natural conversation [with service users and families], its lovely, its wonderful and be able to check in and be able to say, not assume, not assume that they're, not able for it and just having the respect to check in with somebody and take what they say, not to insist, not to assume it's going to go all pear shaped., things will go wrong on the night, Having faith [in service users and family facilitators] and yourself, It's (co-facilitation) just one of the skills that we're trying to develop (C06; II)

C.3 It was revolutionary, in the sense that it was the first program that really did say here's a peer, here's a clinician, here's a group, run it together. You know so that ...just changing the mindset ... allowing people who wanted to do this stuff, to actually do it tangibly and allow people who never did it before and are frightened of it, to see it happen and see nobody exploded and everybody is ok and you know it's all fine. It's not going to be the end of the world, so for that it was absolutely fantastic. (C05; II)

C.4 Oh yes, yeah, absolutely it [EOLAS] started that conversation and the understanding.... we might be afraid of it [coproduction] but things are changing, and a new way of working is here to stay. It's [EOLAS] very a really structured, tangible, ...very practical way of showing this is how it can be done. And if you can do this you have a baseline to work from, it's fantastic. So it definitely helped on a lot of levels, like front line but also management level to actually get your head around this as a service. (C16; II)

C.5 Its positive because people can see how it's worked. . . the feedback has been good [...] even the other day we were at an ADON [Assistant Director of Nursing] meeting looking about starting a hearing voices group and they were talking about training and I could say, look EOLAS started out like this [...] (CO2;II)

C.6 [...] it [EOLAS $]$ was a very positive experience for me. I think it kind of re-energised me in that way, I suppose I achieved one of my goals... it created a bit of energy around what's achieved... we're looking at doing more that involves family and friends you know, so it definitely did [impact]. (F03; FG)

C.7 And you know remunerating people, paying people for their time, ... there's discussions now of family members and service users being on all types of committees. Like the policy committees, the service committee and it's just that its integral to the running of a service. Now there's discussions of how and when we could properly put people in those places and have them take those spaces with their peer views, so actually incorporate it into the running of a service. As opposed to it being a nice little add on. So those conversations have started and EOLAS was the precursor to that. $(\mathrm{C} 07 ; \mathrm{FG})$

C.8 We now have a service user forum, we have service users that are on all our policy committees, you know there's a huge service user involvement. We weren't doing any of the other recovery stuff. EOLAS was up and running on its own for so long that when the rest of it [other recovery initiatives] came on, it was just building on what EOLAS had already delivered and what it was standing for...we'd say it worked in EOLAS so let's try. The value that we've had out of it [EOLAS]. So it was like the tester really. (C02;II)

C.9 [...] we were doing recovery workshops prior to EOLAS even, but mostly around service providers, nurses or psychologists in an addiction centre. This was more, this was more service user or family member. I won't credit EOLAS fully but there's workshops now run and they're actually co-produced with service users and service providers. So, I think EOLAS got people thinking that service users have huge self-experience that we're not harnessing in a positive way for other service users. (F02; II)

C.10 [...] I mean the ultimate sort of expression of social work, of empowerment and recovery, is the development of a service user or a family member [...] the investment for them to then go on and actually be part of delivering a service to other service users or other family members, that's very powerful and, like I said, from the community development it's wonderful to be able to be part of something like that in a clinical setting like mental health. $(\mathrm{C} 10 ; \mathrm{FG})$

C.11 Being able to say about the service [that] a family member or a service user now interacts with their team in a different way, that's incredibly powerful $(\mathrm{C} 12 ; \mathrm{FG})$

Code $\mathrm{C}=$ coordinator; $\mathrm{F}=$ facilitator; $\mathrm{FG}=$ focus group; and $\mathrm{II}=$ individual interview

increased meetings with families at the points of inpatient admission and discharge (B.8) and the inclusion of family members in care planning (B.9). In these services, participants recounted that the team had witnessed the benefits that had accrued to families from having engaged in EOLAS, and decided to try and recreate this in other operational procedures within their service (B.10).

\section{Integration of Co-production into Service Delivery}

Many of the participants reported that the co-produced and co-facilitated tenets of EOLAS had a positive impact on the organizational culture of their services. In many cases, EOLAS afforded participants their first opportunity to build a relationship of partnership with service users and family member facilitators. As a result, participants experienced greater confidence in working and interacting with service users in a more collaborative way and a decrease in risk adversity in all staff was reported (C.1, C.2, C.3). A number of the participants reported that by demonstrating the feasibility and positive impact of co-production approaches, EOLAS assisted with instigating further conversation about how the perspectives of service users and families could be further embedded in the infrastructure and operational spaces within their services (C.4, C.5, C.6, C.7). At 
times when other staff may have been reluctant to start a new group or recovery initiative, EOLAS was cited as an exemplar of how such programmes can work and how best to implement and integrate it into the service (C.6, C.7,C.8). One participant also noted that the successful enacting of co-production in EOLAS contributed to co-production being adopted as the standard approach to other workshops and programmes within the service (C.9). An indication of the extent to which co-production had been integrated into services could be extrapolated from participants' narratives, wherein they expressed pride that their service now acknowledged the expertise and valuable contribution of service users and family members and that their engagement with them was improving (C.10, C.11).

\section{DISCUSSION}

With the growing recognition of the limitations of recovery education that is decoupled from practice (Crowther et al. 2019; Eiroa-Orosa \& García-Mieres 2019) and research indicating that there continues to be a tension between policies that espouse recovery and the lived realities of people using mental health services (Slade et al. 2008), finding workable solutions to enhance the development of recovery-oriented mental health spaces remains a challenge. While the impact of psychoeducation interventions on service users and family outcomes has been reported extensively (Brooke-Sumner et al 2015; Higgins et al. 2020; Lucksted et al. 2012), this is the first study to our knowledge that explores whether being involved with a co-facilitated psychoeducation intervention based on recovery principles reached beyond the intervention itself, in terms of changing the everyday practices of clinicians in the 'real-world' setting.

As an intervention that occurs within the mental health services, the development and delivery of the EOLAS programmes embodied much of the theory and evidence surrounding recovery in its development and delivery, such as its emphasis on service users and family members as equal partners in design and facilitation. In addition, the weight the programmes give to partnership working, shared decision-making, peer support, and adult pedagogy is also in line with the recovery ethos. Findings from the study suggest that as a model of working, the EOLAS programmes provided practitioners with a real-life example of partnership working and peer support in action and offered them a space where service users and family members were no longer service-receivers but 'citizens as equals'
(Voorberg et al. 2015). In so doing, not only did practitioner involvement with the process heighten their awareness of the importance of respecting the centrality of the lived experience of service users and families, but the learning moved beyond the context of the intervention to other areas of institutional practice. In an effort to support recovery-oriented practices such as autonomy, self-direction, self-management, and selfagency (Drake et al. 2010), practitioners were not only transforming their frame of reference in terms of moving beyond the medical view to seeing the person behind the label and diagnosis, and respecting the voice of lived experience, but they were questioning paternalistic practices such as the withholding of information from service users and were working in new ways which recognized people's right to information and involvement. This change in perspective allowed practitioners to engage in new ways of working and to embed this within their practice. From an Irish perspective, this is an important finding given that recent research suggests that Irish mental health services have a significant road to travel before they can say they are truly recovery-oriented (O’Feich et al. 2019).

There was also a pronounced change in practitioners' world view of the role of family members, with participants challenging some of their own and others ingrained beliefs and behaviours in relation to the inclusion of family members within the triad of care. Having engaged with and experienced the feasibility and positive impact of EOLAS, practitioners' fear and anxiety around family involvement was lessened and their self-efficacy was enhanced. Given the importance of building family members' capacity to impact positively on people who experience severe mental distress (NICE 2009; Schiffman et al. 2015) and the evidence internationally and within Ireland that suggests family members are often excluded in the care and decisionmaking process (Cleary et al. 2014; Hungerford \& Richardson 2013; O'Feich et al. 2019; Wyder \& Bland 2014), findings in relation to the development and adoption of more inclusive approaches towards families outside the intervention context are heartening.

Implementation of any healthcare change by its nature is a complex social process, that requires negotiation and development of a shared understanding of the intervention and the 'benefits and risks of the new over the old' (Kitson et al., 2008: 2). Indeed, some of the barriers to implementing recovery-oriented practice cited by practitioners are difficulties in articulating what recovery means and the scarcity of real-life examples of recovery-oriented practices (Le Boutillier et al., 
2015). Hence, melding and embedding recovery-oriented practices into the infrastructure and operational spaces of services not only necessitates having examples, but it requires opinion leaders and champions who will generate enthusiasm around the change (Damschroder et al. 2009). Findings from this study resonate with these views, as the people involved were certainly pointing to EOLAS as an example of a recovery-oriented practice that works. In addition, as opinion leaders the participants involved with EOLAS were exerting influence among their peer colleagues. This influence was now based on their personal experience with programmes within their own service, as opposed to citing some distant evidence that was generated elsewhere. In addition, the influence was now being exerted by peers based on personal experience, an influencing strategy that is often more convincing than influence through authority and status (Damschroder et al. 2009).

\section{LIMITATIONS}

While the study provides useful and positive insights into the impact of the programme on individuals and organization, the self-selection recruitment process may have resulted in study bias with those who were more positive about the programme opting to participate. As a result, it cannot be assumed that the views and experiences presented represent all of those who participated. While the data are strengthened by the triangulation of data from different disciplines and from two different cohorts of people (facilitators and coordinators), the findings are a result of interviews as opposed to observation of practice; therefore, it is not possible to say whether the changes reported were indeed translated into everyday practice. In addition, there is also the potential for the findings to be influenced by social desirability and recall bias or the researchers misinterpreting participants' sentiments as the adequacy of the analysis was not verified with the participants. Finally, the degree of recovery-oriented practice within each service was not measured prior to the study.

\section{CONCLUSION}

Implementing recovery-oriented practices is not without its challenges, and finding new ways of advancing the type of change required is of concern to all involved in mental health care. Findings from this study suggest that the bringing together of service users, family members, and practitioners within a co-facilitated psychoeducation context has potential to be a forum for deconstructing traditional power relationships and pathologizing discourses, and for promoting second-order change around recovery-oriented practice within mental health services.

\section{RELEVANCE FOR CLINICAL PRACTICE}

Effective translation and implementation of recovery policy into practice is not a linear process, that can be achieved by one discrete action such as training. Changing culture and practice is a multifaceted process that requires a range of different techniques. One of the reasons so many new initiatives fail to be sustained is that the focus is often on first-order change, as opposed to changing the less tangible individual and organizational assumptions and thinking. This paper highlights the importance of engaging practitioners in real concrete examples of recovery-oriented practices in action as opposed to decoupling recovery education from practice. It is only through engagement in and reflection on action will practitioners develop the skills and self-efficacy necessary to work in a recovery-oriented way with service users and family members.

\section{ACKNOWLEDGEMENTS}

Thanks to all those who participated in the study, including the Directors of Nursing. We would also like to thank the Health Research Board Ireland and the Health Service Executive who in partnership funded the study through the Applied Partnership Award scheme. The paper is part of a larger study into factors influencing implementation and sustainability of group psychoeducation interventions [Grant Number APA206-1858].

\section{ETHICS APPROVAL}

Ethical approval was granted by the University's Research Ethics Committee and the ethics committees of the services involved.

\section{REFERENCES}

Bonney, S. \& Stickley, T. (2008). Recovery and mental health: a review of the British literature. Journal of Psychiatric and Mental Health Nursing, 15, 140-153. https://doi.org/10.1111/j.1365-2850.2007.01185.x. 
Brooke-Sumner, C., Petersen, I., Asher, L., Mall, S., Egbe, C. O. \& Lund, C. (2015). Systematic review of feasibility and acceptability of psychosocial interventions for schizophrenia in low and middle income countries. BMC Psychiatry, 15, 19. https://doi.org/10.1186/s12888-0150400-6.

Chester, P., Ehrlich, C., Warburton, L., Baker, D., Kendall, E. \& Crompton, D. (2016). What is the work of Recovery Oriented Practice? A systematic literature review. International Journal of Mental Health Nursing, 25, 270285. https://doi.org/10.1111/inm.12241.

Cleary, A. \& Dowling, M. (2009). Knowledge and Attitudes of mental health professionals in Ireland to the concept of recovery in mental health: a questionnaire survey. Journal of Psychiatric and Mental Health Nursing, 16, 539-545.

Cleary, A., Walsh, F. \& Dowling, M. (2014). Family carers: lived experience of caring for relatives with an SMI. British Journal of Mental Health Nursing, 3, 151-156.

Crowther, A., Taylor, A., Toney, R. et al. (2019). The impact of Recovery Colleges on mental health staff, services and society. Epidemiology and Psychiatric Sciences, 28, 481488. https://doi.org/10.1017/s204579601800063x.

Damschroder, L. J., Aron, D. C., Keith, R. E., Kirsh, S. R., Alexander, J. A. \& Lowery, J. C. (2009). Fostering implementation of health services research findings into practice: a consolidated framework for advancing implementation science. Implementation Science, 4, 50. https://doi.org/10.1186/1748-5908-4-50.

Department of Health and Children (2006). A Vision for Change: Report of the Expert Group on Mental Health Policy. Dublin: The Stationery Office.

Doyle, L., McCabe, C., Keogh, B., Brady, A. M. \& McCann, M. (2019). An overview of the qualitative descriptive design within nursing research. Journal of Research in Nursing, https://doi.org/10.1177/1744987119880234.

Drake, R., Deegan, P. \& Rapp, C. (2010). The Promise of Shared Decision Making in Mental Health. Psychiatric rehabilitation journal, 34, 7-13. https://doi.org/10.2975/34. 1.2010.7.13.

Eiroa-Orosa, F. J. \& Garcia-Mieres, H. (2019). A systematic review and meta-analysis of recovery educational interventions for mental health professionals. Administation and Policy in Mental Health, 46, 724-752.

Ellison, M. L., Belanger, L. K., Niles, B. L., Evans, L. C. \& Bauer, M. S. (2018). Explication and definition of mental health recovery: a systematic review. Administration and Policy in Mental Health, 45, 91-102.

Gaffey, K., Evans, D. S. \& Walsh, F. (2016). Knowledge and attitudes of Irish Mental Health Professionals to the concept of recovery from mental illness - five years later. Journal of Psychiatric and Mental Health Nursing, 23, 387-398.

Gilburt, H., Slade, M., Bird, V., Oduola, S. \& Craig, T. K. (2013). Promoting recovery-oriented practice in mental health services: a quasi-experimental mixed-methods study. BMC Psychiatry, 13, 167.
Glaser, B. G. \& Strauss, A. L. (1967). The Discovery of Grounded Theory: Strategies or Qualitative Research. Chicago: Transaction Publishers.

Health Service Executive (2017). Best Practice Guidance for Mental Health Services: Supporting you to meet Regulatory Requirements and towards Continuous Quality Improvement. https://www.hse.ie/eng/services/list/4/mentalhealth-services/mental-health-guidance/best-practice-guida nce/documents/best-practice-guidance-for-mental-health-se rvices.pdf. Accessed: 17 February 2020.

Higgins, A. \& McGowan, P. (2014). Recovery and the recovery ethos: challenges and possibilities. In: A. Higgins \& S. McDaid (Eds). Mental Health in Ireland; Policy, Practice and Law (pp. 61-78). Dublin: Gill \& Macmillan.

Higgins, A., Murphy, R., Barry, J. et al. (2020). Scoping review of factors influencing the implementation of group psychoeducational initiatives for people experiencing mental health difficulties and their families. Journal of Mental Health, 1-14. https://doi.org/10.1080/09638237. 2020.1714002 .

Hungerford, C. \& Richardson, F. (2013). Operationalising recovery-oriented services: the challenges for carers. Advances in Mental Health, 12, 11-21.

Kitson, A. L., Rycroft-Malone, J., Harvey, G., McCormack, B., Seers, K. \& Titchen, A. (2008). Evaluating the successful implementation of evidence into practice using the PARiHS framework: theoretical and practical challenges. Implementation Science, 3, 1. https://doi.org/ 10.1186/1748-5908-3-1.

Kwasnicka, D., Dombrowski, S. U., White, M. \& Sniehotta, F. (2016). Theoretical explanations for maintenance of behaviour change: a systematic review of behaviour theories. Health Psychology Review, 10, 277-296. https://d oi.org/10.1080/17437199.2016.1151372.

Le Boutillier, C., Slade, M., Lawrence, V. et al. (2015). Competing priorities: staff perspectives on supporting recovery. Administration and Policy in Mental Health, 42, 429-438. https://doi.org/10.1007/s10488-014-0585-x.

Lucksted, A., McFarlane, W., Downing, D. \& Dixon, L. (2012). Recent developments in family psychoeducation as an evidence-based practice. Journal of Marital and Family Therapy, 38, 101-121.

McCabe, R., Whittington, R., Cramond, L. \& Perkins, E. (2018). Contested understandings of recovery in mental health. Journal of Mental Health, 27, 475-481.

McFarlane, W. R., Dixon, L., Lukens, E. \& Lucksted, A. (2003). Family psychoeducation and schizophrenia: A review of the literature. Journal of Marital and Family Therapy, 29, 223-245.

Mental Health Reform (2012). Promoting Improved Mental Health Services: Guiding a Vision for Change Manifesto. Dublin: Mental Health Reform.

National Institute for Health and Care Excellence (2009). Schizophrenia: Core Interventions in the Treatment and Management of Schizophrenia in Adults in Primary and Secondary Care. London: National Institute for Health and Clinical Excellence. 
NVivo. NVivo qualitative data analysis software; QSR International Pty Ltd. Version 12, 2018.

O’Féich, P., Mitchell, K., Pérez, S. \& McDaid, S. (2019). My Voice Matters: Report on a National Consultation with Family, Friends and Carers/Supporters of Mental Health Service Users. Dublin: Mental Health Reform.

Onken, S. J., Craig, C. M., Ridgway, P., Ralph, R. O. \& Cook, J. A. (2007). An analysis of the definitions and elements of recovery: a review of the literature. Psychiatric Rehabilitation Journal, 31, 9-22.

Ramon, S., Healy, B. \& Renouf, N. (2007). Recovery from mental illness as an emergent concept and practice in Australia and the UK. International Journal of Social Psychiatry, 53, 108-122. https://doi.org/10.1177/ 00020764006075018.

Repper, J. (2012). Recovery and Social Inclusion in Mental Health: Learning from Lived Experience. Hoboken, United States: John Wiley and Sons Ltd.

Schiffman, J., Reeves, G. M., Kline, E. et al. (2015). Outcomes of a family peer education program for families of youth and adults with mental illness. International Journal of Mental Health, 44, 303-315.

Slade, M. (2009). Personal Recovery and Mental Illness: A Guide for Mental Health Professionals. Cambridge: Cambridge University.
Slade, M. (2013). 100 Ways to Support Recovery. A guide for mental health professionals. Rethink recovery series: volume 1. (2nd Edition). London: Rethink.

Slade, M., Amering, M. \& Oades, L. (2008). Recovery: an international perspective. Epidemiologia e Psichiatria Sociale, 17, 128-137.

Slade, M., Adams, N. \& O’Hagan, M. (2012). Recovery: Past progress and future challenges. International Review of Psychiatry, 24, 1-4.

Slade, M., Amering, M., Farkas, M. et al. (2014). Uses and abuses of recovery: implementing recovery-oriented practices in mental health systems. World Psychiatry, 13, 12-20.

Stickley, T., Higgins, A., Meade, O. et al. (2016). From the rhetoric to the real: A critical review of how the concepts of recovery and social inclusion may inform mental health nurse advanced level curricula - The eMenthe project. Nurse Education Today, 37, 155-163.

Voorberg, W. H., Bekkers, V. J. J. M. \& Tummers, L. G. (2015). A systematic review of co-creation and coproduction: embarking on the social innovation journey. Public Management Review, 17, 1333-1357.

Wyder, M. \& Bland, R. (2014). The recovery framework as a way of understanding families' responses to mental illness: balancing different needs and recovery journeys. Australian Social Work, 67, 179-196. 